\title{
FORMULATION AND EVALUATION OF ANTIMICROBIAL GELS FOR THE TREATMENT OF PARONYCHIA
}

\section{SHAN MOHANAN*, NABEELA RASHEED, BIMAL RAJ K. S.}

Department of Pharmaceutics, Amrita School of Pharmacy, Amrita Vishwa Vidyapeetham, Amrita Institute of Medical Science, Kochi, Kerala, India

Email: shanm@aims.amrita.edu

Received: 03 Jul 2018, Revised and Accepted: 12 Sep 2018

\section{ABSTRACT}

Objective: The aim of the study was to design and develop a gel based drug delivery system containing combinational drugs (ketoconazole, neomycin sulphate and diclofenac) for the effective treatment of Paronychia.

Methods: The drugs used are ketoconazole, neomycin sulphate and diclofenac. The first two drugs provide an antifungal and antibacterial action and the last drug with a pain relieving effect. Two formulations of gels F1 and F2 were prepared using polymers like carbopol 934 and xanthan gum respectively. The amounts of drugs and other ingredients were kept as constant in both formulations. The prepared formulations were then evaluated by visual examination, $\mathrm{pH}$, drug content, spredability, extrudability, drug release study, in vitro antibacterial study, in vitro antifungal study, stability studies and in vivo antibacterial study.

Results: The obtained results were analyzed and compared. All the test results were within the accepted limit. The physicochemical properties of the gels were assessed and it was found that the two formulations have enough gel consistency with good spreadability and extrudability. The drug content and drug release studies of the prepared gels were done and the results showed that the all the three drugs were properly loaded into the gel system, with good drug release profile. The antimicrobial activities of the formulated gels were proved by both in vitro antifungal and antibacterial studies. The in vivo antibacterial studies revealed a significant reduction in bacterial count in wistar rats treated with prepared gel when compared with standard drug solution. From among all the developed formulations, F1 formulation with carbopol 934 has got a slight superior property when compared with formulation F2 xanthan gum as gelling agent.

Conclusion: On the basis of the evaluation studies it was concluded that the drugs (ketoconazole, neomycin sulphate and diclofenac) were successfully incorporated into the different topical gel preparations with good physicochemical properties and antimicrobial activity. Therefore, it was concluded that our formulae could be very promising topical alternative for the treatment of Paronychia.

Keywords: Paronychia, Gel, Topical formulation, Carbopol, Xanthan gum, Ketoconazole, Neomycin, Diclofenac, Antibacterial study, Drug delivery

(C) 2018 The Authors. Published by Innovare Academic Sciences Pvt Ltd. This is an open access article under the CC BY license (http://creativecommons.org/licenses/by/4.0/) DOI: http://dx.doi.org/10.22159/ijap.2018v10i6.28266

\section{INTRODUCTION}

Nowadays different methods like spreading, rubbing, spraying, instillation are used as various mechanisms for topical preparations; it can be applied directly to the body [1]. Topical route is one of the most effective routes of drug administration for treating the skin disorders and they can enhance drug delivery through systemically and non-systemically [2]. The structure of nail consists of nail matrix, nail plate, nail bed, cuticle, nail folds [3] (fig. 1). The nail bed contains two portions (germinal matrix and sterile matrix), which are involved in production, migration and maintenance of nail [4].

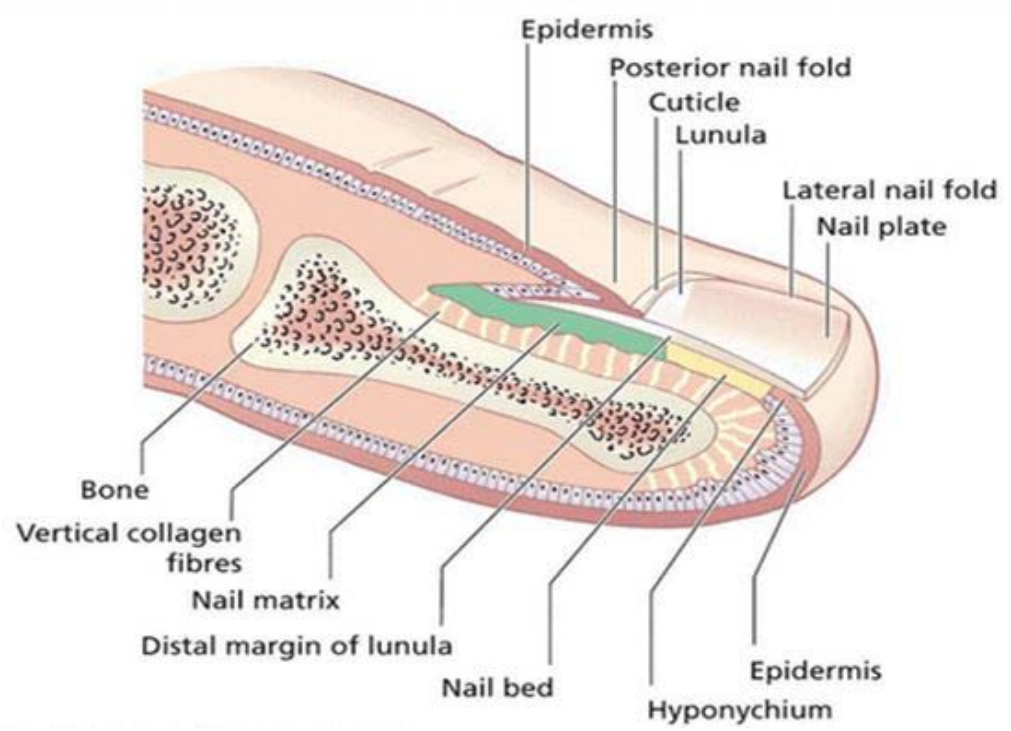

Fig. 1: Longitudinal section of nail [22] 
Paronychia is a type of inflammatory disease, occurs in tissues surrounding of the nail plate. It is a most affected infection of the hand. Paronychia is mainly two types acute and chronic. Acute Paronychia is mainly seen in people who bite their nails, long nails or occurs in manicures. The disease etiology is that this type infection will break the soft tissue seal on dorsal periphery of the nail, they will enter and forming colonies after formation of abscess occurs by the offending organism. The disease starts in the lateral nail folds and it will spread other parts, Staphylococcus aureus is the disease causing organism $[4,5]$.

Chronic Paronychia is persistent type infection, disease affected mainly in the eponchyium, it is somewhat different from acute Paronychia. The Paronychia is mainly seen in people they are chronically exposed to water, alkali etc. The etiology is similar like acute Paronchyia. It is caused by bacterial infection; continue by super infection and colony formation of eponchyium with a fungus such as Candida albicans. The symptoms or signs of chronic Paronychyia are the characteristics of longitudinal grooves on the surface of the nail plate, followed by long term damage to the germinal tissues in the eponychium $[4,5]$. The acute and chronic Paronychia affected fingers is represented in fig. 2.

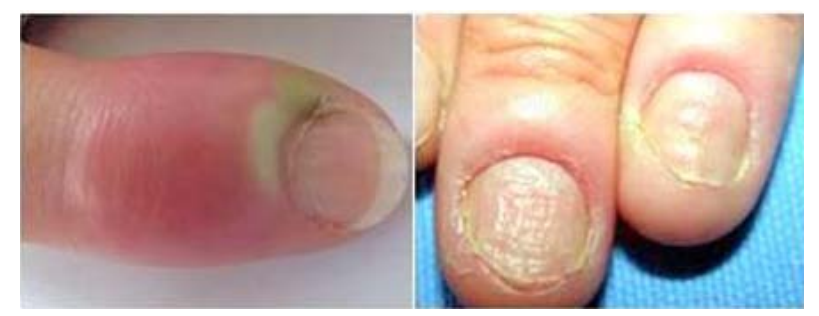

Fig. 2: Acute and chronic paronychia affected fingers [4]

Surgical treatment is another approach towards Paranochyia [6]. Currently there are no marketed formulations are available in the market to treat Paranochyia. Gel is a semisolid system contains two phases, a gelling agent and a liquid. Topical formulations have lot of application than other routes, like they will attain local action, percutaneous penetration of the medicament or they having an emollient as well as protective action. The drug inside the gel has the ability to penetrate the skin and provide action at the site [7].

Due to the non availability of a suitable dosage form to treat Paronychia and the difficulty in assessing the causative agent (bacteria, fungus or both) in the beginning of infection has lead to develop gel based drug delivery system containing combinational drugs for the effective treatment of Paronychia. The drugs used are ketoconazole, neomycin sulphate and diclofenac. The first two drugs provide an antifungal and antibacterial action and the last drug with a pain relieving effect. As Paronychia causes a nail piercing pain and the causative agents cannot be detected in the beginning the prepared gel system will be helpful in treating the people with Paronychia.

\section{MATERIALS AND METHODS}

\section{Materials}

Ketoconazole, neomycin sulphate and diclofenac were obtained as a gift samples from IPCA laboratories Ltd, Mumbai (India). Carbopol 934 and xanthan gum were from Sance pharmaceuticals, Kerala (India). Methyl paraben, propylene glycol and other reagents were of the Pharmacopoeial grade.

Preparation of standard graphs of ketoconazole, neomycin and diclofenac

$100 \mathrm{mg}$ of ketoconazole was dissolved in water and the absorbances of diluted concentrations were measured out in UV at $660 \mathrm{~nm}$. The same method was followed for both neomycin and diclofenac but the absorbance was determined at $277 \mathrm{~nm}$ and $276 \mathrm{~nm}$ respectively $[8,26]$.

\section{Compatibility study by FTIR}

In order to study the drug compatibility in the formulations, FTIR spectrum of drugs with polymers were taken. It was done by $\mathrm{KBr}$ pellet method using FTIR. FTIR spectra of ketoconazole, neomycin, ketocinazole+neomycin, carbopol 934, xanthan gum, carbopol 934+ ketoconazole, carbopol 934+neomycin, xanthan gum+ketoconazole and xanthan gum+neomycin were taken [8].

\section{Solubility}

Solubility study was done using different solvent system such as water, ethanol and phosphate buffer (pH 5.5 and 7.4) [9].

\section{Formulation study}

Working formula was for a quantity of $10 \mathrm{~g}$ of gel. Initially $0.5 \mathrm{~g}$ of carbopol 934 was taken in a beaker and dispersed with sufficient quantity of water using glass rod. Then it was allowed to get hydrate. After that it was neutralized with triethanolamine. Then accurate amount of drug was added with gentle stirring and the desired gel was formed [1]. In the second formulation (F2), $0.5 \mathrm{~g}$ of xanthan gum was replaced with $0.5 \mathrm{~g}$ carbopol 934. The final weight of the formulation was maintained as $10 \mathrm{~g}$ [10]. Working formula for formulation of gel is depicted in table 1 .

Table 1: Working formula for formulation of gel

\begin{tabular}{llll}
\hline S. No. & Ingredients & $\mathbf{F}_{\mathbf{1}}$ & \\
\hline 1 & Ketoconazole & $0.4 \mathrm{~g}$ & \\
2 & Neomycin sulphate & $0.1 \mathrm{~g}$ & \\
3 & Diclofenac & $0.2 \mathrm{~g}$ & \\
4 & Carbopol 934 & $0.5 \mathrm{~g}$ & \\
5 & Xanthan gum & & \\
6 & Propylene glycol & $4 \mathrm{ml}$ & \\
7 & Glycerin & $2 \mathrm{ml}$ & \\
8 & Triethanolamine & $0.5 \mathrm{~g}$ & \\
\end{tabular}

\section{Evaluation of gel}

\section{Physiochemical parameters}

The prepared gels were evaluated for its physicochemical properties like clarity, colour, odour, grittiness and pH. The clarity was examined by visual examination against black or white background and the presence of gritty particles in prepared gels was tested microscopically. The prepared formulations were spread on a mounting glass plate and viewed under microscope [12]. The $\mathrm{pH}$ of the prepared gel formulations was determined by digital $\mathrm{pH}$ meter (Systronics $\mathrm{pH}$ meter Model 6), it was calibrated using standard buffer solutions at $\mathrm{pH} 4,7$ and $9[11,22]$.

\section{Spreadability}

It is determined by the following method. The instrument consists of a wooden block, and a pulley at one end. First of all a glass was fixed to the wooden block using an adhesive. About $2 \mathrm{~g}$ was gel was placed on the glass. Another slide of same dimension (with a hook) was placed over the fixed slide and the gel got sandwiched. Almost $1 \mathrm{~kg}$ weight was placed over the slide to remove the air entrapment. Then a weight of $30 \mathrm{~g}$ is attached to the hook of the slide with a string and allows some time to move the top slide through the fixed slide. Notice the time (in s) taken up by the top slide to cover a distance of $4.6 \mathrm{~cm}$. A shorter interval indicates better spreadability [13]. 
Spreadability, $S=M(L \div T)$

$S=$ Spreadability $M=$ Weight in pan

$L=$ Length moved by the glass slide $T=$ time taken to separate the slides

\section{Extrudability study}

This method was used to analyze the force required to squeeze the content out of the tube. aluminium collapsible tube filled with $10 \mathrm{~g}$ gels was compressed and extrudability of the formulation was determined in terms of weight in grams required to extrude a $0.5 \mathrm{~cm}$ ribbon of gel in $10 \mathrm{~s}$ [14].

\section{Drug content determination}

The gel having a weight of $500 \mathrm{mg}$ was weighed and solubilized in $50 \mathrm{ml}$ of phosphate buffer solution (PBS) pH 5.5 and shakes well to extract the drug and filtered. The drug content was analysed spectrophotometrically (ketoconazole $660 \mathrm{~nm}$, neomycin $277 \mathrm{~nm}$, diclofenac $276 \mathrm{~nm}$ ) [15].

\section{In vitro drug release study}

The study was done using Franz diffusion cell with cellophane membrane as barrier and $100 \mathrm{ml}$ of PBS pH5.5 was used in the receptor compartment, then $1 \mathrm{~g}$ of gel (expected to contain $40 \mathrm{mg}$ of ketoconazole, $10 \mathrm{mg}$ neomycin and $20 \mathrm{mg}$ of diclofenac) was spread uniformly on the membrane. The drug concentration on the receptor fluid was determined spectrophotometrically (ketoconazole $660 \mathrm{~nm}$, keomycin $277 \mathrm{~nm}$, diclofenac $276 \mathrm{~nm}$ ) against appropriate blank (sampling Time 0, 5, 10, 15, 30, 60, $120 \mathrm{~min}$ ). The experiment was carried out in triplicate [16].

\section{In vitro antibacterial study}

An agar-well diffusion method was used for determination of antibacterial activity of neomycin sulphate. The gel samples were dissolved in PBS, pH5.5. The cultured bacteria (Staphylococcus aureus) were suspended in sterile water and diluted to 10 colony found per unit $(\mathrm{CFU}) / \mathrm{ml}$. The suspension $(100 \mu \mathrm{l})$ was spread onto the surface of nutrient agar medium. Wells (4.6 $\mathrm{mm}$ in diameter) were cut with a sterile borer and $60 \mu \mathrm{l}$ formulations were added into them. PBS solution was used as negative control. Incubation of the inoculated plates was done at $37^{\circ} \mathrm{C}$ for $24 \mathrm{~h}$. The diameter of inhibition zone (DIZ) was evaluated and thereby antibacterial activity also. All tests were performed in triplicates $[17,23]$.

\section{In vitro antifungal study}

The antifungal activity of ketoconazole was done by agar-well diffusion method, in which the Candida albicans was inoculated with molten potato dextrose agar at $45^{\circ} \mathrm{C}$ and allowed to set in a petri dish. Wells ( $4.6 \mathrm{~mm}$ in diameter) were cut in a similar way as for the antibacterial activity and $60 \mu \mathrm{l}$ formulations were added into them. PBS was used to prepare the negative control. The plates were incubated at $28^{\circ} \mathrm{C}$ for $3 \mathrm{~d}$ after which DIZ were measured [18].

\section{Stability study}

The prepared formulations (F1 and F2) were maintained at room temperature over a period of two months in three types of storage containers (plastic transparent, glass transparent and collapsible metallic tubes). The physical appearance, homogeneity, syneresis and drug contents were evaluated after 2 mo [19]. The experiments were performed in triplicates.

\section{Optimization of gels}

The prepared gels were optimized by using the evaluated data. All the test parameters were taken into account [20].

\section{In vivo antibacterial study}

The study was conducted at central animal house, Amrita Institute of Medical Science, Kochi. All the experimental procedures were approved (IAEC/2017/3/11) and performed in accordance with the standards prescribed by the institutional animal ethical committee. 12 adult male rats of Wistar strain with body weighing 300 to $350 \mathrm{~g}$, maintained under controlled light and temperature were used in this study. The animals were caged (one animal per cage) with standard food and water ad libitum. The animals were grouped into three, Group 1: F1 formulation Group 2: neomycin solution and Group 3: control (water for injection). Staphylococcus aureus bacteria were obtained from microbiology lab, Amrita School of Pharmacy and were used in this study. The anesthetized animals were placed in prone position, and it was sterilized with alcoholiodine. A punch was used to achieve the wounds of approximately 8 mm diameter allowing the removal of a circular area of skin, on the middle portion of the medium sagittal plane. After its preparation, the wounds were colonized with a standard solution of Staphylococcus aureus and quantitation of bacterial population was done. Then, the 3 groups were applied with equal aliquots of F1 formulation, neomycin solution and water for injection respectively. Each group of mice receiving a particular treatment regimen was housed separately in a ventilated cage with appropriate bedding, food, and water. Mice were checked twice daily during infection and treatment to ensure no adverse reactions were observed. After $48 \mathrm{~h}$, exudates were collected from the wounds for quantitation of bacterial population. The materials were processed and cultured on selective MacConkey's agar medium. The agar plates were incubated at $37^{\circ} \mathrm{C}$ and examined after $24 \mathrm{~h}$. Any growth in the plates of bacteria of the same biotype as cultured in the wounds was considered positive and expressed as colony forming units per gram of tissue [21].

\section{RESULTS AND DISCUSSION}

Absorbance values of ketoconazole, neomycin and diclofenac are shown in (table 2) and standard graphs were plotted between concentrations on $\mathrm{X}$ axis, absorbance on $\mathrm{Y}$ axis (fig. 3).

The FTIR analysis (fig. 4, fig. 5 and fig. 6) showed that there are no incompatibilities in the formulation. All the identification peaks of drugs are existing in the formulation also. The identification peaks of ketoconazole are $\mathrm{C}=0$ Stretching vibration of carbonyl group-1653 $\mathrm{cm}^{-1} 1, \mathrm{C}-\mathrm{O}$ stretching of aliphatic ether groups-1031.92 $\mathrm{cm}^{-1}, \mathrm{C}-\mathrm{O}$ stretching of cyclic ether-1271 $\mathrm{cm}^{-1}$ and chlorine group- $727 \mathrm{~cm}^{-1}$. The identification peaks of neomycin $\mathrm{OH}$ stretching- $3500 \mathrm{~cm}^{-1}, \mathrm{~N}-\mathrm{H}$ bending- $1666 \mathrm{~cm}^{-1}$ and ether frequency- $1180 \mathrm{~cm}^{-1}$. So FTIR analysis revealed that the drug combinations are compatible and stable with other drugs and gelling agents $[10,11,25]$.

\section{Solubility}

Solubility study was done using different solvent system. The obtained result was shown in (table 4)

Table 2: Absorbance values of Ketoconazole, Neomycin and Diclofenac

\begin{tabular}{|c|c|c|c|c|c|}
\hline $\begin{array}{l}\text { Concentration } \\
\text { ketoconazole }(\mu \mathrm{g} / \mathrm{ml})\end{array}$ & $\begin{array}{l}\text { Absorbance } \\
\text { at } 660 \mathrm{~nm}\end{array}$ & $\begin{array}{l}\text { Concentration } \\
\text { neomycin }(\mu \mathrm{g} / \mathrm{ml})\end{array}$ & $\begin{array}{l}\text { Absorbance } \\
\text { at } 277 \mathrm{~nm}\end{array}$ & $\begin{array}{l}\text { Concentration } \\
\text { diclofenac }(\mu \mathrm{g} / \mathrm{ml})\end{array}$ & $\begin{array}{l}\text { Absorbance } \\
\text { At } 276 \mathrm{~nm}\end{array}$ \\
\hline 0 & 0 & 0 & 0 & 0 & 0 \\
\hline 0.25 & 0.142 & 0.10 & 0.006 & 10 & 0.112 \\
\hline 0.3 & 0.286 & 0.20 & 0.013 & 20 & 0.223 \\
\hline 0.35 & 0.431 & 0.30 & 0.019 & 30 & 0.32 \\
\hline 0.4 & 0.569 & 0.40 & 0.025 & 40 & 0.441 \\
\hline 0.45 & 0.723 & 0.50 & 0.033 & 50 & 0.545 \\
\hline
\end{tabular}



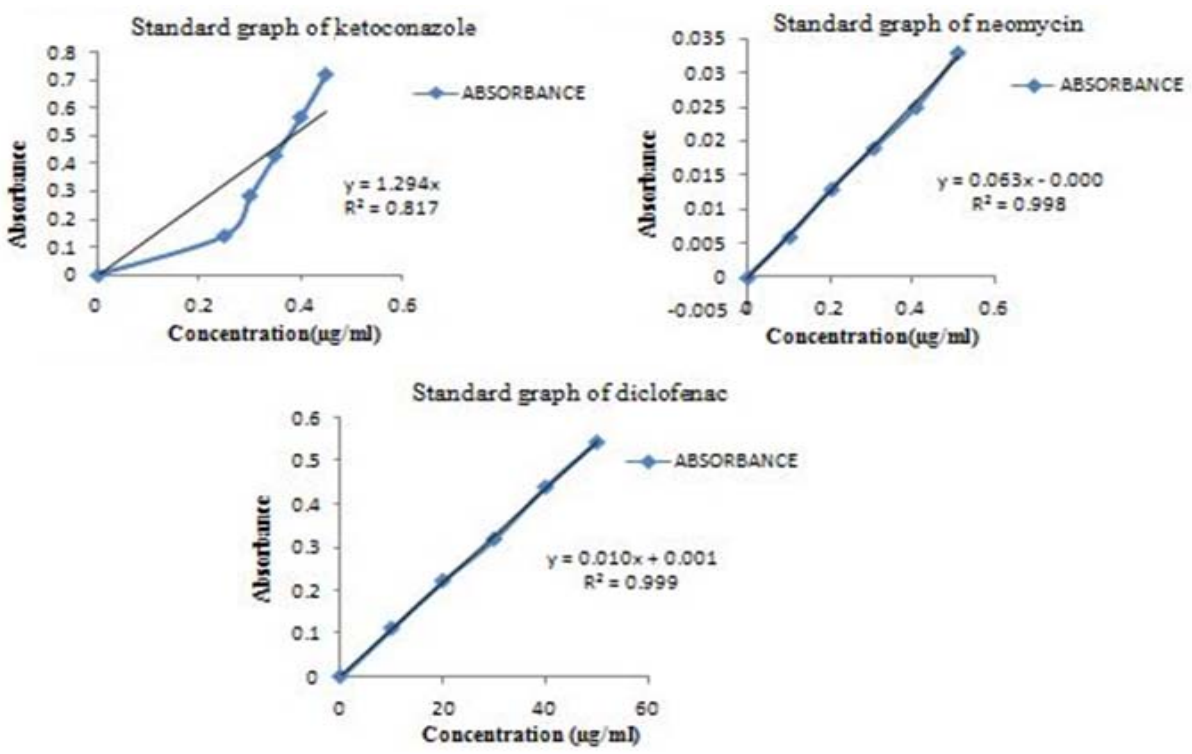

Fig. 3: Standard graphs of ketoconazole, neomycin, diclofenac compatibility study by FTIR

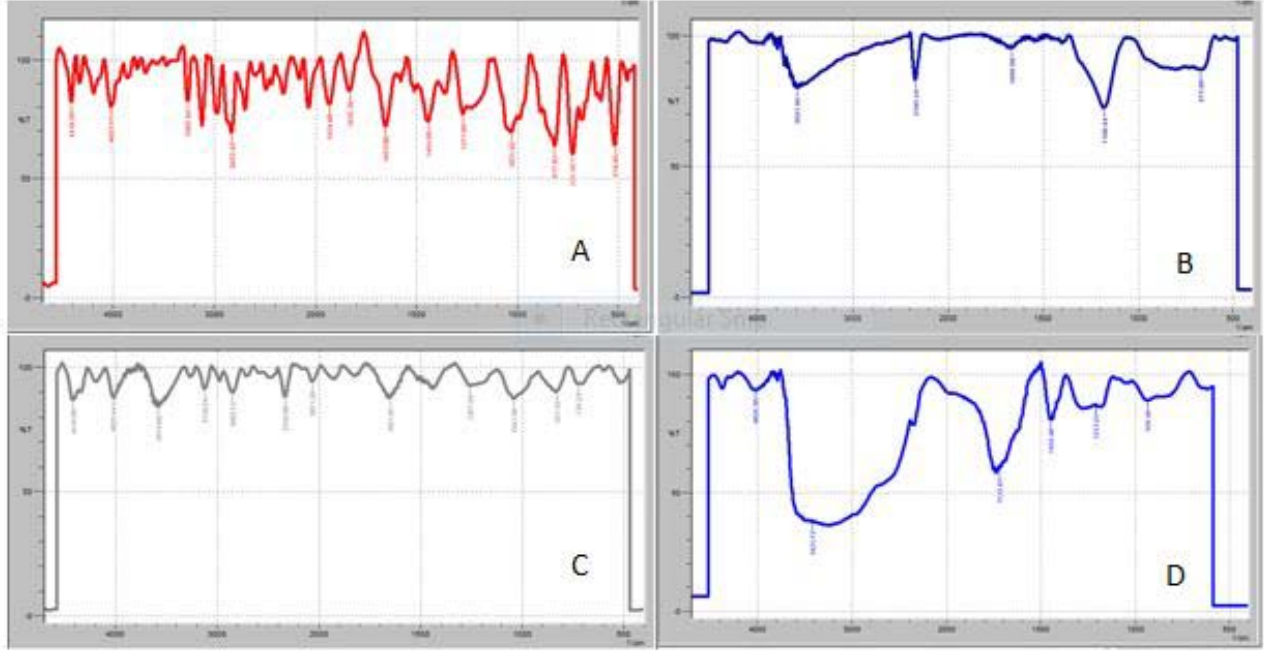

Fig. 4: FTIR spectra of A) Ketoconazole, B) Neomycin, C)Ketoconazole+neomycin and D) carbopol 934

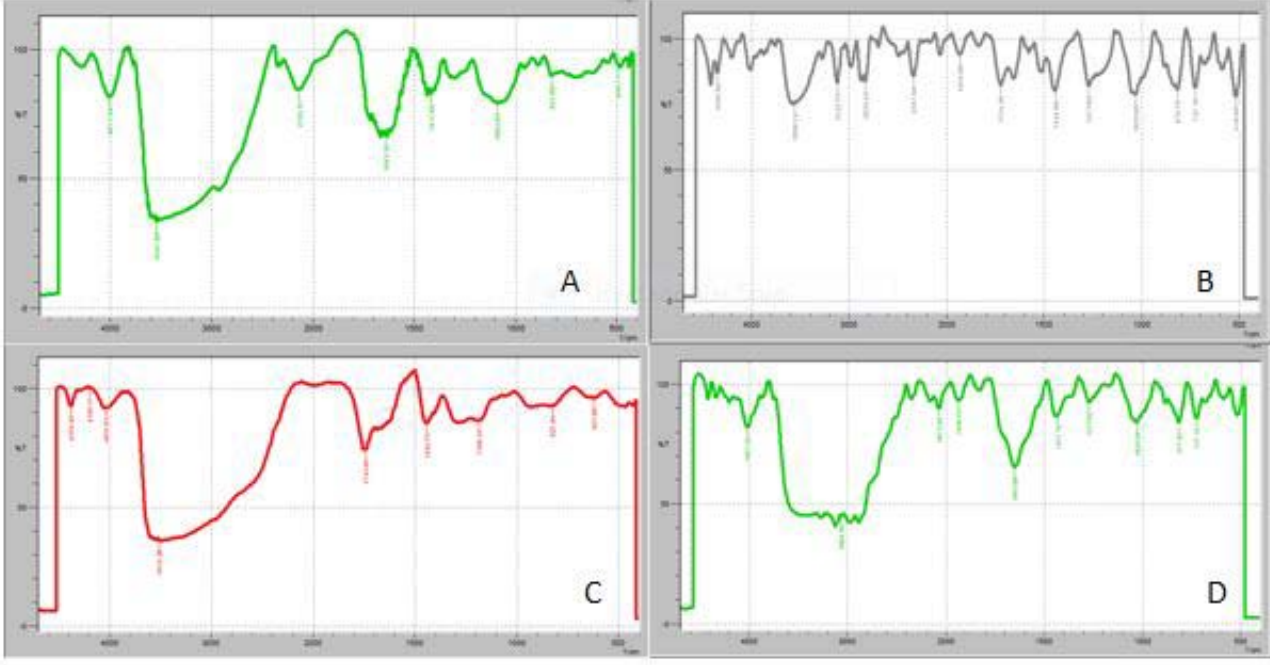

Fig. 5: FTIR spectra of A) Xanthan Gum, B) Carbopol 934+Ketoconazole, C) Carbopol 934+Neomycin and D) Xanthan Gum+Ketoconazole 


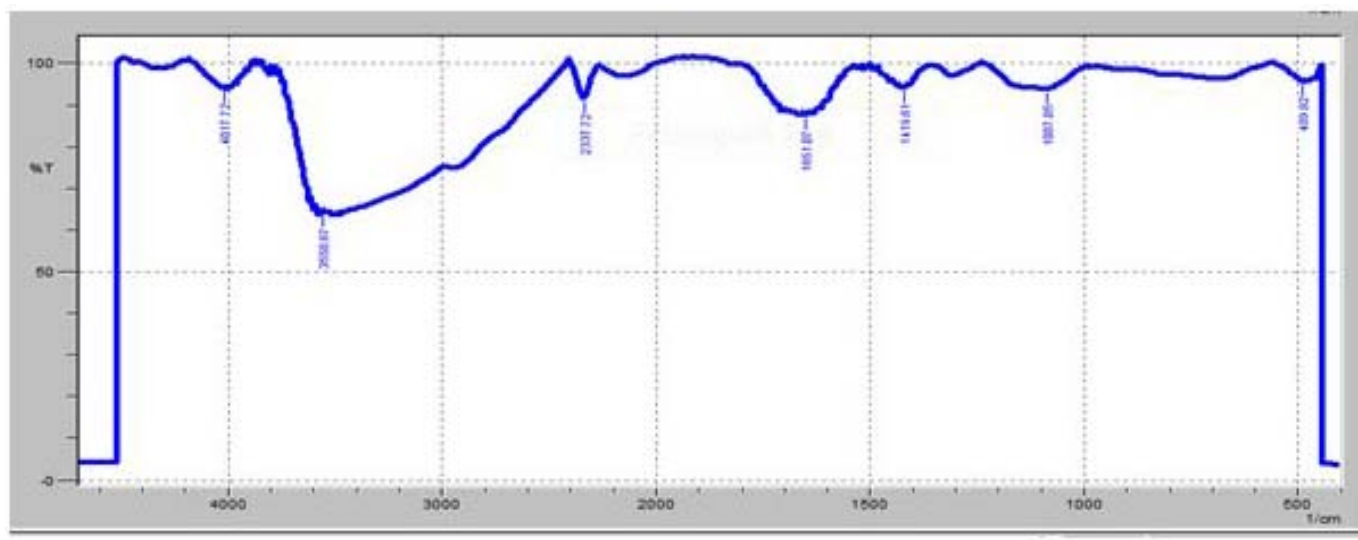

Fig. 6: FTIR spectrum of xanthan gum+neomycin

Table 3: Solubility profile of ketoconazole, neomycin and diclofenac in different solvents

\begin{tabular}{llll}
\hline \multirow{2}{*}{ Drug } & \multicolumn{2}{l}{ Solubility in solvents } & \\
\cline { 2 - 3 } & Water & Ethanol & Phosphate buffer (pH 5.5 and 7.4) \\
\hline Ketoconazole & Soluble & Soluble & Soluble \\
Neomycin & Soluble & Insoluble & Soluble \\
Diclofenac & Soluble & Soluble & Soluble \\
$(\mathrm{n}=3)$ & & & \\
\hline
\end{tabular}
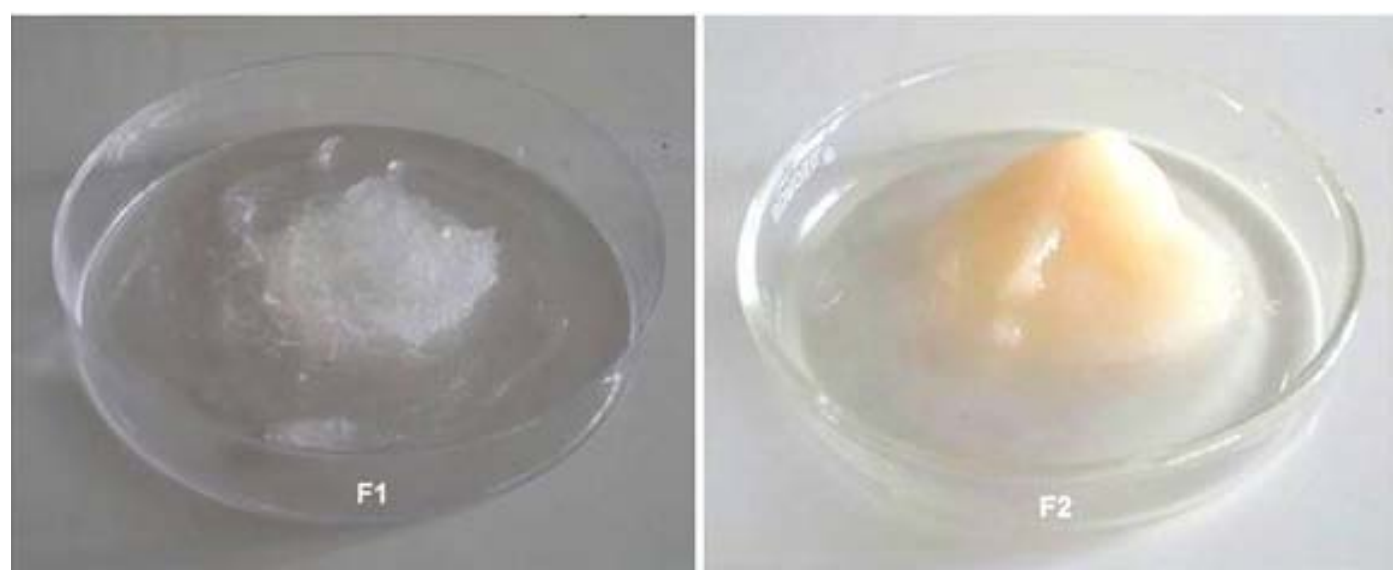

Fig. 7: The prepared gels F1 (carbopol 934) and F2 (xanthan gum) as gelling agents

\section{Formulation study}

The formulations of gels were prepared as prescribed method and it is shown in (fig. 7).

\section{Physiochemical parameters}

The prepared formulations were evaluated for clarity test and the study results show that, both the gels were clear and free of particles. The formulations exhibited a good homogeneity. The gel with carbopol 934 as gelling agent showed a good transparency when compared with the gel with xanthan gum as gelling agent. Both the formulations were viscous in nature. Xanthan gum showed a translucent nature. The formulated gels were visually evaluated and it was found to be clear and white cloudy appearance for gel with carbopol 934 as gelling agent whereas the other formulation appeared as slight yellowish color with good clarity. Both the formulations have got a rose fragrance. The samples were free of particulate matter was seen under light microscope. Hence the gel is free of particular matter and can be used for any topical preparation. The $\mathrm{pH}$ of the formulated gels was found to be $5.7 \pm 0.1$ for carbopol 934 gel and $6.4 \pm 0.1$ for xanthan gum gel. The obtained $\mathrm{pH}$ resembles to skin $\mathrm{pH}$ and compatable for topical formulation [10, 12, 15]. Physicochemical properties of the gels are summarized in table 4 .

Table 4: Physicochemical properties of the gels

\begin{tabular}{lllll}
\hline Topical gels & Color & Homogenity & pH & Odour \\
\hline $\mathrm{F}_{1}$ & Transparent & Homogenous & $5.7 \pm 0.1$ & Rose fragrance \\
$\mathrm{F}_{2}$ & Translucent yellowish & Homogenous & $6.4 \pm 0.1$ & Rose fragrance \\
\hline
\end{tabular}

Data expressed as mean $\pm \mathrm{SD}(\mathrm{n}=3)$ 


\section{Spreadability and extrudability study}

The spreadability test was performed as prescribed in the procedure. The test results revealed that the gel with carbopol 934 as gelling agent has got a higher spreadability when compared with xanthan gum gel formulation. The values of spreadability were $4.6 \mathrm{~cm}$ and $4.2 \mathrm{~cm}$ respectively for both carbopol 934 and xanthan gum gels $[18,20]$. The slight change in spreadability may be due to the change in polymer. All the two formulations showed a good extrudability. There is no significance change in the extrudabilities of F1 and F2. So, plug flow is limited in this formulation and is easy to squeeze out the formulation from the collapsible tube and there is a uniformity of drug contents in the extruded mass [20].

\section{Drug content determination}

Results of drug content are shown in (table 5). After the formulation of the two types of gels, the drug content of the formulated gel was estimated and the results were in the official limits. The drug content determination also showed the uniformity of drug distribution in the gel $[18,20]$

Table 5: Drug content of the gels

\begin{tabular}{llll}
\hline Topical gels & Ketoconazole & Neomycin & Diclofenac \\
\cline { 2 - 4 } & \%W/W & \% W/W & \% W/W \\
\hline $\mathrm{F}_{1}$ & $98.4 \pm 0.7$ & $97.4 \pm 1.1$ & $99.2 \pm 0.8$ \\
$\mathrm{~F}_{2}$ & $98.0 \pm 1.0$ & $96.0 \pm 0.9$ & $98.6 \pm 1.0$ \\
\hline
\end{tabular}

*Data expressed as mean \pm SD $(n=3)$

\section{In vitro drug release study}

It was observed that the release of the drugs from its different formulae didn't show any significant difference in drug release. .On comparison of the obtained in vitro data; it was found that F1 showed a bit faster release of drugs when compared with F2. The amount of the drug released after $2 \mathrm{~h}$ were $40.1 \pm 1.22 \%$, $40.1 \pm 1.24 \%$, and $53 \pm 1.24 \%$ for ketoconazole, neomycin and diclofenac respectively from $\mathrm{F} 1$, whereas in $\mathrm{F} 2$ the release was $38 \pm 1.27 \%, 38 \pm 1.20 \%$ and $52 \pm 1.27 \%$ respectively.

On analysis, it was found that almost $30 \%$ of the drug is been released within $5 \mathrm{~min}$. So it is an indication that the gel will act very fast in the infected area. Especially the drug release for diclofenac was almost $40 \%$ within $5 \mathrm{~min}$ and may get a faster pain relieving action in the affected area. It is shown in (table 6).

Table 6: In vitro drug release profile

\begin{tabular}{|c|c|c|c|c|c|c|}
\hline \multirow[t]{2}{*}{ Time (min) } & \multicolumn{3}{|l|}{ F1 } & \multicolumn{3}{|l|}{ F2 } \\
\hline & K1 & N1 & D1 & K2 & N2 & D2 \\
\hline 0 & 0 & 0 & 0 & 0 & 0 & 0 \\
\hline 5 & $31.0 \pm 1.25$ & $30.0 \pm 1.22$ & $41.5 \pm 1.21$ & $29.0 \pm 1.22$ & $28.0 \pm 1.24$ & $38.0 \pm 1.20$ \\
\hline 10 & $32.2 \pm 1.20$ & $32.5 \pm 1.25$ & $42.5 \pm 1.22$ & $30.2 \pm 1.25$ & $29.2 \pm 1.25$ & $39.2 \pm 1.22$ \\
\hline 15 & $33.4 \pm 1.21$ & $33.7 \pm 1.20$ & $45.5 \pm 1.20$ & $31.4 \pm 1.28$ & $30.4 \pm 1.22$ & $40.4 \pm 1.24$ \\
\hline 30 & $35.0 \pm 1.22$ & $36.5 \pm 1.27$ & $48.5 \pm 1.25$ & $33.9 \pm 1.24$ & $32.4 \pm 1.24$ & $44.0 \pm 1.28$ \\
\hline 60 & $38.5 \pm 1.20$ & $38.0 \pm 1.22$ & $51.0 \pm 1.24$ & $36.0 \pm 1.27$ & $35.5 \pm 1.27$ & $48.0 \pm 1.25$ \\
\hline 120 & $40.1 \pm 1.22$ & $40.1 \pm 1.24$ & $53.0 \pm 1.24$ & $38.0 \pm 1.27$ & $38.0 \pm 1.20$ & $52.0 \pm 1.27$ \\
\hline
\end{tabular}

*Data expressed as mean \pm SD $(n=3)$ K-ketoconazole, N-neomycin and D-diclofenac

\section{In vitro antibacterial and antifungal study}

The antibacterial activities of neomycin from its different gel formulae were compared. The results were satisfactory. In this case the DIZ was same $(33 \pm 1 \mathrm{~mm})$ for both F1 and F2. The results of all formulae were satisfactory for antifungal study also. A slight increased activity was observed with F1 where the inhibition zone reaches $37 \pm 1 \mathrm{~mm}$ whereas $\mathrm{F} 2$ where the inhibition was $35 \pm 1 \mathrm{~mm}$ $[17,18]$. There is not much significant difference in antifungal activity of ketoconazole in both the formulations.

\section{Stability study}

On evaluation of the formulations, it was found that there is some slight change in the physical characters of the formulations (F1and F2) that stored in plastic container when compared with other containers. It is shown in (table 7). The formulations stored in plastic containers showed a red coloration; it may be due to the leaching of the container. The formulations in other containers were found to be stable with no coloration. Other physical parameters were same for all the formulations during the entire storage period. There were no syneresis and grittiness in all the stored formulations [19]. The drug content results revealed that there is no significant change in drug content after stability study.

\section{Optimization of gel}

The optimization of the prepared gels was done by comparing the results of different evaluation tests. By comparing all the data it was found that the F1 formulation with carbopol 934 as gelling has got a slight superior property when compared with F2; where xanthan gum was used as gelling agent. The change in evaluation test results may be mainly due to the change in polymer.

Table 7: Stability data of F1 and F2 formulations after two months (K-ketoconazole)

\begin{tabular}{|c|c|c|c|c|c|c|c|}
\hline \multirow[t]{2}{*}{ Formulation } & \multirow[t]{2}{*}{ Container } & \multicolumn{4}{|l|}{ Physical Parameters } & \multirow[t]{2}{*}{ Syneresis } & \multirow[t]{2}{*}{ Drug content, $\mathrm{K}$} \\
\hline & & Color & Homogeneity & Odour & Grittiness & & \\
\hline F1 & Plastic & Red & Homogeneous & Rose & No & No & $98.0 \pm 0.1 \%$ \\
\hline $\mathrm{F} 2$ & Plastic & Red & Homogeneous & Rose & No & No & $96.5 \pm 0.5 \%$ \\
\hline F1 & Glass & White transparent & Homogeneous & Rose & No & No & $98.1 \pm 0.8 \%$ \\
\hline $\mathrm{F} 2$ & Glass & Yellowish translucent & Homogeneous & Rose & No & No & $97.2 \pm 0.5 \%$ \\
\hline F1 & C. Tube & White transparent & Homogeneous & Rose & No & No & $98.5 \pm 0.4 \%$ \\
\hline $\mathrm{F} 2$ & C. Tube & Yellowish translucent & Homogeneous & Rose & No & No & $98 \pm 0.6 \%$ \\
\hline
\end{tabular}

*Data expressed as mean \pm SD $(n=3), K$-Ketoconazole 


\section{In vivo antibacterial study}

The change in colony forming units for each group was investigated and expressed as mean values. Comparison of the values of CFU between the start and end times for each group were calculated (table 8). The values were calculated in terms of $\%$ variation in CFU in each group also. From the results, it was found that there is so much reduction in the CFU in the case of group $1(92.38 \%)$ and group 2 (95.76\%), which were treated with F1 formulation and neomycin solution respectively whereas in Group 3, a sharp increase in CFU was found. At the same time there is no significant difference in reduction in the CFU between Group 1 and 2. However in group 3 treated with distilled water showed a $68 \%$ increment in CFU. The study reveals that the Formulation 1 has significant antibacterial action in reducing the Staphylococcus aureus and can be used in the treatment of Paronychia. In accordance with the presented results, it can conclude that Formulation 1 can be an alternative for current treatment and surgical method $[21,23]$.

Table 8: Comparison of the values of CFU between the start and end times for each group

\begin{tabular}{llllll}
\hline Animal number & Group 1 & & Group 2 & & Group 3 \\
\cline { 2 - 6 } & Start & End & Start & End & Start \\
\hline 1 & 2555 & 230 & 2600 & 108 & 2503 \\
2 & 2203 & 200 & 3033 & 55 & 2700 \\
3 & 2400 & 150 & 2879 & 230 & 2400 \\
4 & 2144 & 130 & 3100 & 100 & 2452 \\
Mean & $2325.5 \pm 118.1$ & $177.5 \pm 45.7$ & $2903 \pm 222.1$ & $123.5 \pm 74.8$ & $2513.8 \pm 131.0$ \\
\hline
\end{tabular}

*Data expressed as mean \pm SD $(n=4)$

\section{CONCLUSION}

On the basis of the evaluation studies we can conclude that the drugs (ketoconazole, neomycin and diclofenac) were successfully incorporated into the different topical gel preparations. From among all the developed formulation, the formula F1 (carbopol 934 as gelling agent) showed comparatively good spreadability, extrudability, drug content, drug release and antimicrobial effect. But there is not much significant difference in the evaluated parameters of both formulations. The antifungal and antibacterial effects of these formulations also found to be satisfactory. Therefore, it was concluded that our formulae could be very promising topical alternative for the treatment of Paronychia. However, further preclinical and clinical studies are required to prove its application in human.

\section{ACKNOWLEDGEMENT}

Authors are thankful to Amrita Vishwa Vidyapeetham, Kerala for providing infrastructure facility and chemicals to do the work.

\section{AUTHORS CONTRIBUTIONS}

All the author have contributed equally

\section{CONFLICTS OF INTERESTS}

Authors have no conflict of interest

\section{REFERENCES}

1. Doaa AH, Dalia A, Sally A, Abdel H, Mohamed AE. Formulation and evaluation of fluconazole topical gel. Int J Pharm Pharm Sci 2012;4:176-83.

2. Vineet R, Khushbu G, Shikha B, Vijay KG. Management of chronic paronychia. Indian J Dermatol 2014;59:1-14.

3. Bendar MS, Lane LB. Eponychial marsupialization and nail removal for surgical treatment of chronic paronychia. J Hand Surg Am 1991;16:314-7.

4. Dimitris R, Geogrge L, Stamatis G. Acute and chronic paronychia. Am Fam Physician 2008;77:339-46.

5. Keyser JJ, Eaton EG. Surgical cure of chronic paronychia by eponychial marsupialization. Plast Reconstr Surg 1976;58:66-70.

6. Abrams RA, Botte MJ. Hand infections: treatment recommendations for specific types. J Am Acad Orthop Surg 1996;4:219-30.

7. Kumar R, Katare OP. Lecithin organogels as potential phospholipid structured system for topical drug delivery. AAPS PharmSciTech 2005;6:298-310.

8. V Rajpal, DP S Kohli. Herbal drug industry. 1st ed. New Delhi: Business Horizons; 2009.

9. Vinod MT, Bharath WT, Bharat RP. Formulation and characterization of ketoprofen topical gel. Int J Curr Pharm Clin Res 2014;4:35-42.
10. Tanwar YS. Formulation and evaluation of topical diclofenac sodium gel using different gelling agent. AJPRHC 2011;4:1-6.

11. Japan P, Brijesh P, Hardeepsingh B, Kaushal P, Manish P. Formulation and evaluation of topical aceclofenac gel using different gelling agents. Int J Drug Dev Res 2011;4:23-9.

12. Subrahmanyam CVS. Text book of physical pharmaceutics. 2nd ed. New Delhi: Vallabh Parakashan; 2009.

13. Saad SD, Mir NA, Hajera T, Mazharuddin K. Studies on antibacterial and antifungal activity of pomegranate (Punica granatum L.). American-Eurasian J Agric Environ Sci 2010;9:273-81.

14. Kumar TG, Kaur LP. Formulation and evaluation of topical gel of aceclofenac. J Drug Delivery Ther 2013;3:51-3.

15. Bharat $\mathrm{P}$, Atul K, Ajay C. Formulation and evaluation of gel containing miconazole nitrate an antifungal agent. Int J Pharma Res Rev 2013;2:18-28.

16. Marwa HS, Ghada FM. Evaluation of topical gel bases formulated with various essential oils for antibacterial activitry against methicillin resistant Staphylococcus Aureus. Trop J Pharm Res 2013;12:877-84.

17. Susan H. Comparison of in vitro dialysis release methods of loperamide encapsulated liposomal gel for topical drug delivery. Int J Nanomed 2014;9:735-44.

18. Enkelegda G, Entela H, Skerdilaid X, Ledjan M. Formulation and in vitro evaluation of diclofenac sodium gel. Int J Pharm Pharm Sci 2014;6:12-7.

19. Safeela N, Fatima Q. UV spectrophotometric assay of diclofenac sodium available brands. J Innovation Pharma Bio Sci 2011;3:14-7.

20. Ajinkya MB, Manjusha ND. Formulation and evaluation of herbal antimicrobial gel containing Musa acumulata leaves extract. J Pharmacogn Phytochem 2016;5:1-3.

21. Paulo CC, Filipe AR, Ana CGB, Baldemoro AKS, Daniel MP, Nadia $\mathrm{CB}$, Ana PCM, Geisa PO. Proyecto academico sin fines de lucro, desarrollado bajo la iniciativa de acceso abierto. Conscientiae Saude 2008;7:423-9.

22. Samantha E. Fungal nail infection: diagnosis and management. Br Med J 2009;18:26-30.

23. Nina IH, Marline N, Urip H. Formulation and evaluation of herbal antibacterial gel containing ethanolic extract of mikania micrantha kunth leaves. Asian J Pharm Clin Res 2018;11:429-31.

24. Lakshmi PK, Marka K, Aishwarya S, Shyamala B. Formulation and evaluation of ibuprofen topical gel: a novel approach for penetration enhancement. Int J Appl Pharm 2011;3:25-30.

25. Nidhi C, Chakraborthy GS. Formulation and evaluation of herbal hydro gel from Hibiscus rosa-sinensis. Int J Curr Pharm Res 2014;6:14-6

26. Amita HP, Riddhi MD. Formulation and evaluation of Sustained Release In situ ophthalmic gel of neomycin sulphate. Bull Pharm Res 2015;5:1-5. 